\title{
Toward a mechanistic understanding of anaerobic nitrate-dependent iron oxidation: balancing electron uptake and detoxification
}

\author{
Hans K. Carlson ${ }^{1}$, lain C. Clark ${ }^{1,2}$, Ryan A. Melnyk ${ }^{1}$ and John D. Coates ${ }^{1}{ }^{*}$ \\ Department of Plant and Microbial Biology, University of California Berkeley, Berkeley, CA, USA \\ 2 Department of Civil and Environmental Engineering, University of California Berkeley, Berkeley, CA, USA
}

Edited by:

Eric Roden, University of

Wisconsin-Madison, USA

\section{Reviewed by:}

Amy Michele Grunden, North Carolina

State University, USA

Flynn Picardal, Indiana University,

USA

\section{*Correspondence:}

John D. Coates, Department of Plant and Microbial Biology, University of

California Berkeley, Berkeley, CA

94720, USA.

e-mail: jdcoates@berkeley.edu

\begin{abstract}
The anaerobic oxidation of Fe(II) by subsurface microorganisms is an important part of biogeochemical cycling in the environment, but the biochemical mechanisms used to couple iron oxidation to nitrate respiration are not well understood. Based on our own work and the evidence available in the literature, we propose a mechanistic model for anaerobic nitratedependent iron oxidation. We suggest that anaerobic iron-oxidizing microorganisms likely exist along a continuum including: (1) bacteria that inadvertently oxidize $\mathrm{Fe}$ (II) by abiotic or biotic reactions with enzymes or chemical intermediates in their metabolic pathways (e.g., denitrification) and suffer from toxicity or energetic penalty, (2) Fe(II) tolerant bacteria that gain little or no growth benefit from iron oxidation but can manage the toxic reactions, and (3) bacteria that efficiently accept electrons from Fe(II) to gain a growth advantage while preventing or mitigating the toxic reactions. Predictions of the proposed model are highlighted and experimental approaches are discussed.
\end{abstract}

Keywords: nitrate dependent ferrous iron oxidation, NDFO, Fe(II) oxidoreductase, electron sparing, Acidovorax

\section{INTRODUCTION}

In recent years, significant progress has been made toward understanding the biochemical mechanisms used by bacteria to catalyze the aerobic and anaerobic oxidation of $\mathrm{Fe}(\mathrm{II})$ in the environment. Recent reviews focus on aerobic/microaerobic iron oxidation (Emerson et al., 2010) and iron oxidation by acidophiles and anoxygenic phototrophs (Bird et al., 2011), however a number of microorganisms have been described which can couple iron oxidation to nitrate reduction (Chaudhuri et al., 2001; Weber et al., 2001, 2006a,b; Finneran et al., 2002; Lack et al., 2002; Muehe et al., 2009) in the absence of oxygen and light. The growth benefit from anaerobic iron oxidation varies widely. In both photosynthetic and nitrate reducing bacteria, oxidation of $\mathrm{Fe}$ (II) may represent an important detoxification strategy (Muehe et al., 2009; Poulain and Newman, 2009), and in some cases may have also evolved into a metabolic strategy (Widdel et al., 1993; Croal et al., 2007; Jiao and Newman, 2007; Muehe et al., 2009; Weber et al., 2009; Chakraborty et al., 2011). In this paper, we suggest that the success of an iron-oxidizing microorganism depends on the extent to which electron donation from Fe(II) can be controlled and toxic reactions prevented or managed. We propose working models to analyze the results of experiments aimed at elucidating the mechanisms of iron oxidation by anaerobic nitrate reducing bacteria. We also highlight some of the predictions of the models that future experiments should address. Our intention is not to exhaustively review the literature, but rather to highlight some of the salient features of anaerobic nitratedependent iron oxidation and provide insight for new research directions.

\section{RUSTING AWAY IN THE DARK, WITHOUT OXYGEN: EVIDENCE FOR ANAEROBIC NITRATE-DEPENDENT IRON OXIDATION BY ENVIRONMENTAL BACTERIA}

Bacterial species that couple the oxidation of $\mathrm{Fe}$ (II) to nitrate reduction have been isolated from a wide range of habitats and are phylogenetically diverse (Hafenbradl et al., 1996; Straub et al., 1996; Chaudhuri et al., 2001). Iron-oxidizing microbes have been demonstrated to oxidize both soluble and insoluble Fe(II) (Widdel et al., 1993; Chaudhuri et al., 2001; Weber et al., 2001, 2006c), and to produce a variety of insoluble $\mathrm{Fe}(\mathrm{III})$ mineral products (Machulla et al., 1998; Straub and Buchholz-Cleven, 1998; Chaudhuri et al., 2001; Weber et al., 2006c). Although the metabolism is based on thermodynamically favorable redox reactions (Koppenol, 1996; Bartberger et al., 2002; Shafirovich and Lymar, 2002; Dutton et al., 2005; Flores-Santana et al., 2011), little is known about the mechanisms used by anaerobic neutrophilic nitrate-dependent iron oxidizers (Weber et al., 2006a; Bird et al., 2011). However, a few studies do suggest an energetic benefit from this metabolism for the organisms involved (Muehe et al., 2009; Weber et al., 2009). Figure 1 presents several conceivable mechanisms for obtaining energetic benefit from iron oxidation catalyzed by anaerobic denitrifying bacteria. Some of these mechanisms may be inducible in specialized iron-oxidizing microorganisms, while others may be general to all nitrate reducing bacteria. One of these mechanisms (electron sparing) includes both enzymatically mediated components and abiotic interactions between $\mathrm{Fe}$ (II) and reactive intermediates resulting in a net energy gain. These mechanisms may be mutually exclusive, but based on reactive species formed during metabolism, it is more likely that hybrid abiotic/biotic 


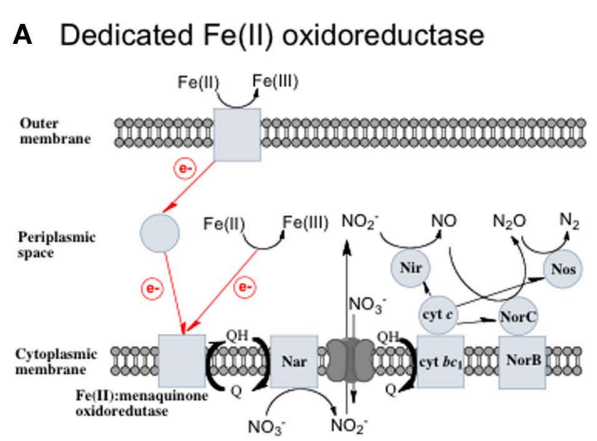

C Cytochrome $b c_{1} \mathrm{Fe}(\mathrm{II})$ oxidoreductase

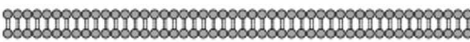

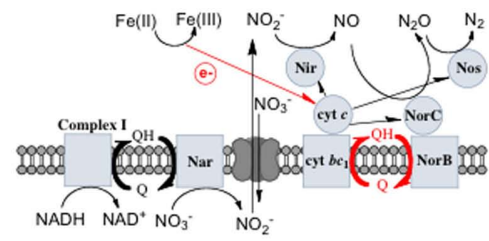

FIGURE 1 | Possible mechanisms for energetic benefit from iron oxidation coupled to nitrate reduction. (A) A true Fe(II):menaquinone oxidoreductase accepts electrons from iron and reduces the quinone pool, (B) Nar accepts electrons from Fe(II) and reduces nitrate cytoplasmically, consuming protons to generate a PMF, $(\mathbf{C})$ the cytochrome $b c_{1}$ complex accepts electrons from Fe(II) and reduces the quinone pool, (D) more protons
B Direct electron donation to Nar

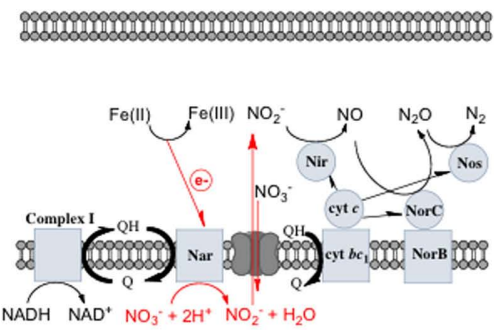

D Electron sparing

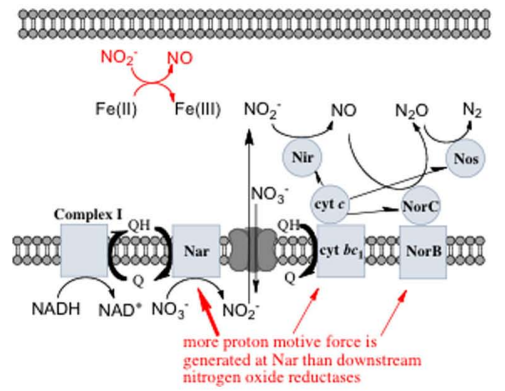

are pumped per electron at Nar than other nitrogen oxide reductases. If abiotic reactions dominate for the reduction of $\mathrm{NO}_{2}^{-}$, an energetic benefit is conferred through an electron sparing mechanism. Nar, nitrate reductase; Nir, nitrite reductase; Nor, nitric oxide reductase; Nos, nitrous oxide reductase; $\mathrm{QH}_{2}$, reduced quinone; $\mathrm{Q}$, oxidized quinone; $b c_{1}$, cytochrome $b c_{1} ;$ cyt $c$, cytochrome $c$. mechanisms are functioning. To the best of our knowledge such hybrid abiotic/biotic mechanisms represent a novel metabolic process in microbiology. Below follows a brief description of these mechanisms and the evidence to support their existence.

\section{A DEDICATED Fe(II) OXIDOREDUCTASE}

A dedicated $\mathrm{Fe}(\mathrm{II})$ : menaquinone oxidoreductase protein, or protein complex, could oxidize iron at the cell surface or in the periplasm and reduce the quinone pool, providing reducing equivalents for downstream nitrogen oxide reductases (Figure 1A) allowing for proton motive force (PMF) generation. This mechanism predicts inducibility of iron oxidation and the expression of a specific protein or proteins in response to $\mathrm{Fe}(\mathrm{II})$.

\section{DIRECT ELECTRON DONATION TO NITRATE REDUCTASE}

In this model a standard membrane bound Nar could serve as the combined $\mathrm{Fe}$ (II) oxidase and nitrate reductase. If Nar can accept electrons from $\mathrm{Fe}(\mathrm{II})$ to catalyze cytoplasmic $\mathrm{NO}_{3}^{-}$reduction to $\mathrm{NO}_{2}^{-}$and $\mathrm{H}_{2} \mathrm{O}$, two protons are consumed in the cytoplasm without the need for electrons from NADH resulting in an enhanced PMF (Figure 1B). Although, this mechanism may be inducible, it is unlikely as Nar will be expressed during nitrate reducing conditions regardless. As such, it could be an inadvertent mechanism of dissimilatory nitrate reduction using Nar. $\mathrm{NO}_{3}^{-}$Transport into the cytoplasm by $\mathrm{NO}_{3}^{-} / \mathrm{NO}_{2}^{-}$antiporters without consumption of periplasmic protons is necessary for this mechanism to generate a
PMF. It is important to note that nitrate reductases with periplasmic sites for $\mathrm{NO}_{3}^{-}$, such as Nap, consume periplasmic protons to reduce nitrate and no energetic benefit would result from $\mathrm{Fe}(\mathrm{II})$ electron donation to catalyze $\mathrm{NO}_{3}^{-}$reduction by Nap.

\section{CYTOCHROME $b c_{1}$ COMPLEX MEDIATED Fe(II) OXIDATION}

A third possibility is that the cytochrome $b c_{1}$ complex can accept electrons from $\mathrm{Fe}$ (II) and reduce the quinone pool This is similar to the proposed mechanism that Acidithiobacillus and anoxygenic phototrophs use to generate $\mathrm{NADH}$ from $\mathrm{Fe}(\mathrm{II})$ oxidation (Figure 1C; Bird et al., 2011). In these metabolisms, the cytochrome $b c_{1}$ complex is proposed to be involved in reverse electron transfer to reduce the quinone pool (Bird et al., 2011). The exact mechanism and the net proton translocation associated with reverse electron transfer by $b c_{1}$ is not well understood, but is thought to be at the expense of the PMF (Ferguson and Ingledew, 2008). For neutrophilic iron oxidation, the redox potential of $\mathrm{Fe}(\mathrm{III}) / \mathrm{Fe}$ (II) is low enough to reduce menaquinone $\left(E^{\circ \prime}=-0.074 \mathrm{~V}\right.$; Wagner et al., 1974; Schoepp-Cothenet et al., 2009). However, for this mechanism to generate a PMF, the quinone pool must obtain protons from the cytoplasm upon reduction by the $b c_{1}$ complex, and release those protons into the periplasm upon oxidation. Coupled to a quinol dehydrogenase, this would provide net proton translocation (Note: some NorBC are quinol dehydrogenases; Kraft et al., 2011). We envision that alternating fluxes of acetate and nitrate in the environment could 
be harnessed by a $b c_{1}$ ferroxidase in this way. When high acetate concentrations are present, electrons flow through cytochrome $c$ to sustain denitrification, and iron oxidation by $b c_{1}$ is minimal. As acetate becomes scarce, the quinone pool is largely oxidized, and electrons from iron could be used to reduce the quinone pool at $b c_{1}$.

\section{ELECTRON SPARING}

A fourth mechanism for obtaining an energetic benefit from $\mathrm{Fe}(\mathrm{II})$ oxidation involves differential electron flow to the terminal reductases. If more protons are translocated per electron at the nitrate reductase (Nar) than at downstream reductases coupled to $b c_{1}$, then a shift in electron flow to Nar would be beneficial (Figure 1D). If this is the case, under heterotrophic growth conditions with excess electron acceptor (e.g., $\mathrm{NO}_{3}^{-}$), abiotic redox reactions between $\mathrm{Fe}(\mathrm{II})$ and $\mathrm{NO}_{2}^{-}$and other nitrogen oxides would allow greater net proton translocation per electron from Complex I. We refer to this phenomenon as electron sparing. More nitrate would be consumed in such a mechanism, but an energetic benefit to the organism would be gained per mole of electron donor (i.e., organic co-substrate, $\mathrm{H}_{2}$ ). This mechanism only applies to iron oxidizers when a co-substrate is available as an electron donor, and could be more pronounced when abiotically produced nitrogen oxide gases are continuously removed, as in flow through experimental setups. However, when electron acceptor is limiting, such reactions are likely to lead to a growth disadvantage due to a loss of electron accepting capacity. This hypothesis can be tested by looking for differences in growth on $\mathrm{Fe}(\mathrm{II})$ under donor or acceptor limiting conditions in batch culture. It is also important to emphasize that the location of the $\mathrm{Fe}$ (II) reaction with $\mathrm{NO}_{2}^{-}$is potentially very important in determining the consequences for the bacterial cell. If the reaction happens in the periplasm, insoluble $\mathrm{Fe}$ (III) crusts may be harmful, but if the reaction happens outside of the cell, the $\mathrm{NO}_{2}^{-}$could react with insoluble $\mathrm{Fe}$ (II) in minerals without negative consequences for the cell.

\section{THINKING OUTSIDE OF THE CELL: EVIDENCE FOR ABIOTIC REDUCTION OF NITROGEN OXIDES CATALYZED BY SOLUBLE $\mathrm{Fe}$ (II) AND INSOLUBLE Fe(II) MINERALS}

Regardless of whether abiotic reactions of nitrogen oxides and $\mathrm{Fe}$ (II) can lead to an energetic benefit through electron sparing, uncoupling the denitrification pathway is likely to create a significant flux of toxic reactive nitrogen species. The characterization of these products and the mechanisms whereby microorganisms cope with the toxicity will lead to an understanding of the benefit or cost of microbial iron oxidation.

The abiotic reaction of nitrate $\left(\mathrm{NO}_{3}^{-}\right)$with soluble $\mathrm{Fe}(\mathrm{II})$ is slow (Moraghan and Buresh, 1977). However, the reaction between $\left(\mathrm{NO}_{2}^{-}\right)$and soluble $\mathrm{Fe}(\mathrm{II})$ is rapid (Moraghan and Buresh, 1977). The products of the abiotic reactions vary with $\mathrm{pH}$ and include $\mathrm{NO}, \mathrm{N}_{2} \mathrm{O}$, and $\mathrm{NH}_{4}^{+}$(Chalamet, 1973; Moraghan and Buresh, 1977). Copper $\left(\mathrm{Cu}^{2+}\right)$ or silver $\left(\mathrm{Ag}^{+}\right)$can catalyze abiotic $\mathrm{NO}_{3}^{-}$reduction coupled to $\mathrm{Fe}(\mathrm{II})$ oxidation at room temperature and neutral pH (Moraghan and Buresh, 1977; Ottley et al., 1997). Green rusts (GR), mixed $\mathrm{Fe}(\mathrm{II}) / \mathrm{Fe}(\mathrm{III})$ hydroxides, can also catalyze the reduction of nitrogen oxides (Figure 2A). As with soluble $\mathrm{Fe}(\mathrm{II}), \mathrm{GR}$ reactions with $\mathrm{NO}_{3}^{-}$and $\mathrm{NO}_{2}^{-}$produce $\mathrm{NO}, \mathrm{N}_{2} \mathrm{O}$, and $\mathrm{NH}_{4}$ depending on the $\mathrm{pH}$ (Figure 2A; Summers and Chang, 1993; Hansen et al., 1994, 1996). It has further been observed that the intercalating anion in the GR mineral affects the rate of $\mathrm{NO}_{3}^{-}$reduction. GR intercalated with chloride $\left(\mathrm{Cl}^{-}\right)$has a 30 - to 40 -fold faster rate of $\mathrm{NO}_{3}^{-}$reduction compared with GR intercalated with sulfate $\left(\mathrm{SO}_{4}^{-}\right)$(Hansen et al., 2001). A number of microorganisms produce GR as intermediates or products of nitrate-dependent iron oxidation (Chaudhuri et al., 2001; Lack et al., 2002). Therefore, it is possible that abiotic reactions catalyzed by GR can contribute to nitrate removal in iron-oxidizing microcosms and cultures during the growth phase, after growth has stopped, or in non-growth cultures in which GR has formed.

\section{A WRENCH IN THE GEARS: EVIDENCE FOR UNCOUPLING OF BACTERIAL DENITRIFICATION BY Fe(II)}

In Escherichia coli, it has been known for some time that the presence of millimolar $\mathrm{Fe}(\mathrm{II})$ and $\mathrm{NO}_{3}^{-}$leads to an uncoupling of electron transport and dissimilatory nitrate reduction resulting in the production of high micromolar to millimolar levels of nitric oxide (NO) and nitrous oxide $\left(\mathrm{N}_{2} \mathrm{O}\right.$; Brons et al., 1991; Figure 2B). Further evidence for uncoupling of nitrate reduction electron transport by $\mathrm{Fe}(\mathrm{II})$ was observed with Shewanella putrefaciens 200 and Paracoccus denitrificans (Cooper et al., 2003; Coby and Picardal, 2005). The location and form of $\mathrm{Fe}(\mathrm{II})$, the $\mathrm{pH}$, and the nitrogen oxide starting material are all likely to contribute to the products of abiotic uncoupling reactions during microbial nitrate and nitrite reduction (Chalamet, 1973; Moraghan and Buresh, 1977; Hansen et al., 2001).

As the reaction between $\mathrm{Fe}(\mathrm{II})$ and $\mathrm{NO}_{3}^{-}$is slow, the first likely point of uncoupling is $\mathrm{Fe}(\mathrm{II})$ oxidation by $\mathrm{NO}_{2}^{-}$to produce $\mathrm{NO}$ and $\mathrm{Fe}$ (III) as initial products (Figure 2B). In previous studies, $\mathrm{NO}$ was found to be produced at a higher rate and accumulate in cultures of heterotrophically grown nitrate reducers in the presence of $\mathrm{Fe}(\mathrm{II})$ (Brons et al., 1991). NO is a gas, and will partition into the headspace of sealed culture tubes, potentially representing a significant loss of electron accepting equivalents in open systems. However, NO is also toxic, and can react with metalloproteins in the cell and components of the electron transport chain, and in the presence of redox active metals can nitrosate thiols (Beckman and Koppenol, 1996). Fortunately, the respiratory NO reductase (Nor) of denitrifying bacteria can reduce NO to less toxic products, and other enzymes involved in the reduction of nitrogen oxides can play a protective role in addition to their respiratory function (Gardner et al., 2002; Gomes et al., 2002; Mills et al., 2008). Nor is independently regulated from other components of the denitrification pathway and can be upregulated to reduce excess NO (Rodionov et al., 2005).

Little $\mathrm{NO}_{2}^{-}$should accumulate in denitrifying cultures as a result of fast abiotic reactions between $\mathrm{NO}_{2}^{-}$and $\mathrm{Fe}(\mathrm{II})$. Contrary to this prediction, some previous studies have measured nitrite accumulation and attributed this finding to the inhibition of nitrite reductase by $\mathrm{Fe}$ (III) precipitation (Straub et al., 1996; Weber et al., 2006b). However, it should be noted that NO (and other nitrogen oxides) will rapidly react with $\mathrm{O}_{2}$ to form nitrite (Feelisch, 1991; Beckman and Koppenol, 1996). If samples are not kept anaerobic 


\section{A Abiotic nitrate reduction by green rust}

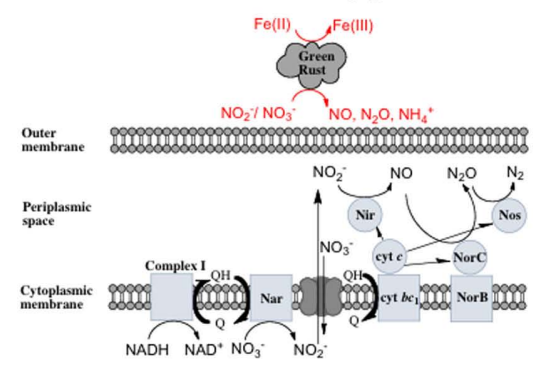

C Efflux pumps for iron export from cells

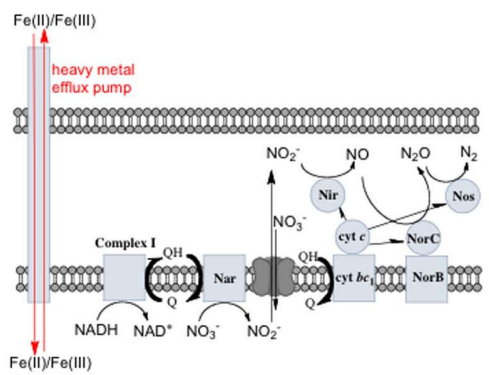

FIGURE 2 | Possible reactions resulting in toxicity and energetic loss during iron oxidation coupled to nitrate reduction and potential microbial responses. (A) Green rusts are capable of catalyzing nitrate reduction coupled to iron oxidation. If they are produced, they will consume $\mathrm{NO}_{3}^{-}$and compete with bacteria for electron acceptor. (B) $\mathrm{NO}_{2}^{-}$ will rapidly react with $\mathrm{Fe}(\mathrm{II})$ to form NO. NO can be further reduced, but can also bind to metalloproteins and disrupt electron transport chains.
B Abiotic NO production

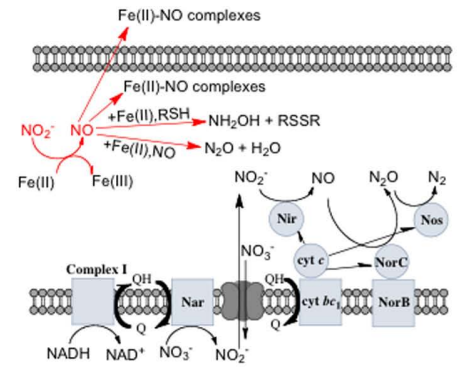

D Low pH or pili/EPS control Fe(III) precipitation

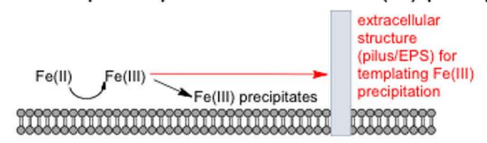

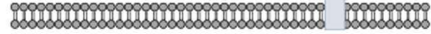

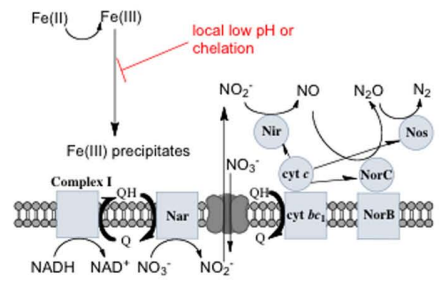

Upregulation of Nor or other NO reductase proteins could protect cells from NO. (C) Soluble Fe(II) or Fe(III) could be exported from cells by heavy metal efflux pumps before it reacts with cellular components (in the case of $\mathrm{Fe}(\mathrm{II})$ ) or precipitates to form mineral crusts (in the case of $\mathrm{Fe}(\mathrm{III})$ ). (D) Extracellular polysaccharides or pili may scaffold the precipitation of Fe(III) outside of cells, or a local low pH or chelators may prevent the precipitation of $\mathrm{Fe}(\mathrm{III})$ in the periplasm. during sample preparation for nitrite analysis, the nitrite analyzed may also represent other reactive nitrogen species (Straub et al., 1996; Weber et al., 2006b). Some researchers have suggested that $\mathrm{NO}_{2}^{-}$may function as a shuttle to oxidize iron (Miot et al., 2009a; Chakraborty et al., 2011). We find this hypothesis plausible, and have also proposed that abiotic reactions between $\mathrm{Fe}(\mathrm{II})$ and $\mathrm{NO}_{2}^{-}$ could lead to an energetic benefit through an electron sparing mechanism (Figure 1D).

Excess NO produced by bacteria can also further react to form other compounds. NO will bind to free Fe(II) outside of the cell to form stable iron-nitrosyl complexes (Brons et al., 1991; Figure 2B), but will not bind tightly to $\mathrm{Fe}(\mathrm{III})$. Thus, as $\mathrm{Fe}(\mathrm{II})$ oxidation continues, bound NO will be released. Further reduction of $\mathrm{NO}$ can produce the high energy intermediate nitroxyl $\left(\mathrm{NO}^{-}, \mathrm{HNO}\right)$ which can react with thiols to form hydroxylamine (Flores-Santana et al., 2011), or with another nitroxyl to form $\mathrm{N}_{2} \mathrm{O}$ (Beckman and Koppenol, 1996; Flores-Santana et al., 2011; Figure 2B). Some evidence for nitroxyl as an intermediate in denitrification exists (Turk and Hollocher, 1992), and though the redox potential of the $\mathrm{NO} / \mathrm{NO}^{-}$couple is $-0.8 \mathrm{~V}$ vs. $\mathrm{SHE}$ at $\mathrm{pH}$ 7 (Bartberger et al., 2002), the evidence for its presence and a role in other biological systems is increasing. It is possible that a nitroxyl-like species is an intermediate in biological and chemical denitrification pathways (Flores-Santana et al., 2011).

\section{IN A METAL CAGE: Fe(II) DIFFUSION INTO CELLS AND CELL ENCRUSTATION BY THE FORMATION OF PERIPLASMIC AND OUTER MEMBRANE IRON OXIDE MINERALS}

Iron-oxidizing bacteria produce insoluble $\mathrm{Fe}(\mathrm{III})$ minerals as a product. In some cases, these insoluble minerals have been found associated with the periplasm of cells or on the cell surface. Precipitation outside of cell was observed for Rhodobacter capsulatus SW2 (Kappler and Newman, 2004), and a local drop in pH around the cells was proposed to be involved in preventing precipitation in the periplasm (Kappler and Newman, 2004). In contrast, precipitates in the periplasm were observed in the nitrate-dependent iron oxidizer Acidovorax sp. Strain BoFeN1 (Kappler et al., 2005, 2010; Miot et al., 2009b). More specifically, these precipitates appear to be initially localized to the periplasmic face of the inner membrane (Miot et al., 2011).

The insolubility of $\mathrm{Fe}(\mathrm{III})$ creates a serious problem for iron oxidizers. If ferric minerals begin to crystallize in the periplasm or on the surface of cells, damage to membranes, proteins, and other cellular components will likely ensue, and under extreme cases, the permeability of the cells to soluble nutrients may be impaired. If $\mathrm{Fe}$ (II) enters the cytoplasm, it can replace other metals in proteins, and participate in damaging redox reactions (Crichton, 2009). Cellular Fe(II) homeostasis is carefully controlled in microbes by the activity of metalloregulatory proteins such as 
the ferric uptake regulator, Fur (Crichton, 2009). Efflux pumps are widely used by bacteria for the export of toxic metal ions, and at the expense of ATP, provide a means of exporting metals from the cell (Nies, 2003). Most studies investigating transcriptional responses of microorganisms to iron have focused on iron uptake under iron limiting conditions, but environmental conditions certainly exist where a cell is faced with iron overload. It seems likely that under high iron conditions, efflux pumps would be upregulated (Figure 2C). Consumption of ATP by these pumps may attenuate any energy gains as a result of $\mathrm{Fe}(\mathrm{II})$ oxidation by the organism. Although significant research effort has focused on these efflux pumps, most studies have looked at their expression in the presence of metals other than $\mathrm{Fe}(\mathrm{II})$ (Nies, 2003).

It has been suggested that $\mathrm{Fe}$ (II) bound to cell surface minerals can further catalyze denitrification reactions (Coby and Picardal, 2005), and that these mineral deposits may prevent the diffusion of soluble electron acceptors into the cell. It appears that some bacteria are able to avoid periplasmic encrustation, but the mechanism for exporting the $\mathrm{Fe}$ (III) before it precipitates is not known. It has been suggested that a local low $\mathrm{pH}$ in the periplasm and outside of cells could prevent Fe(III) precipitation, and extracellular polysaccharide fibers or pili may provide a scaffold for mineralization outside of the cell (Figure 2D; Miot et al., 2009b).

\section{A BALANCING ACT: HARNESSING ELECTRONS FROM Fe(II) AND AVOIDING TOXICITY}

Electrons from the oxidation of $\mathrm{Fe}(\mathrm{II})$ are thermodynamically poised to reduce $\mathrm{NO}_{3}^{-}$(Koppenol, 1996; Bartberger et al., 2002; Shafirovich and Lymar, 2002; Dutton et al., 2005; Flores-Santana et al., 2011), but the kinetics of the abiotic reactions are slow (Moraghan and Buresh, 1977). Therefore, high rates of nitratedependent $\mathrm{Fe}$ (II) oxidation observed in many studies indicate that $\mathrm{Fe}$ (II) is enzymatically coupled to the reduction of nitrate to at least nitrite. This is further supported by the results of washed

\section{REFERENCES}

Bartberger, M. D., Liu, W., Ford, E., Miranda, K. M., Switzer, C., Fukuto, J. M., Farmer, P. J., Wink, D. A., and Houk, K. N. (2002). The reduction potential of nitric oxide (NO) and its importance to NO biochemistry. Proc. Natl. Acad. Sci. U.S.A. 99, 10958-10963.

Beckman, J. S., and Koppenol, W. H. (1996). Nitric oxide, superoxide, and peroxynitrite: the good, the bad, and ugly. Am. J. Physiol. 271, C1424C1437.

Bird, L. J., Bonnefoy, V., and Newman, D. K. (2011). Bioenergetic challenges of microbial iron metabolisms. Trends Microbiol. 19, 330-340.

Brons, H. J., Hagen, W. R., and Zehnder, A. J. (1991). Ferrous iron dependent nitric oxide production in nitrate reducing cultures of Escherichia coli. Arch. Microbiol. 155, 341-347.

cell suspension experiments where nitrate-dependent oxidation occurs rapidly with $\mathrm{Fe}(\mathrm{II})$ as the sole electron donor (Chaudhuri et al., 2001; Lack et al., 2002; Weber et al., 2006b). If the reactions were entirely abiotic, the rate of $\mathrm{Fe}$ (II) oxidation should not differ from the heat-killed controls.

A number of bacteria are capable of growth in the presence of $\mathrm{Fe}$ (II) (Weber et al., 2006a), and in some cases, growth benefit from neutrophilic iron oxidation has been reported (Muehe et al., 2009; Weber et al., 2009; Chakraborty et al., 2011). It is clear from these studies that the culture conditions can greatly affect the growth benefit associated with iron oxidation (Weber et al., 2009; Chakraborty et al., 2011). What is not clear, however, are the exact mechanisms whereby diverse species of bacteria harness $\mathrm{Fe}$ (II) electrons in the presence of competing abiotic reactions with nitrogen oxides.

\section{CONCLUSION}

Our central hypothesis is that the mechanisms used by neutrophilic anaerobic nitrate-dependent iron-oxidizing bacteria likely exist along a continuum from purely abiotic reactions between microbially produced nitrogen oxides to mixed biotic/abiotic mechanisms involving direct electron donation from iron to cellular components. This fascinating and geochemically important process may also be unique in that the microbial metabolisms themselves might take advantage of abiotic reactions, for example by using $\mathrm{NO}_{2}^{-}$as a shuttle (Miot et al., 2009a; Chakraborty et al., 2011), or through the electron sparing hypothesis in Figure 1D. With the growing number of pure isolates of robust iron oxidizing microorganisms, we are optimistic that the mechanistic proposals in this paper can be tested in the laboratory.

\section{ACKNOWLEDGMENTS}

Research on microbial Fe(II) oxidation in the John D. Coates laboratory is supported by funding from the Energy Biosciences Institute, CA, USA.

Chemical and biological interactions during nitrate and goethite reduction by Shewanella putrefaciens 200. Appl. Environ. Microbiol. 69, 3517-3525.

Crichton, R. R. (2009). Iron Metabolism: From Molecular Mechanisms to Clinical Consequences. Chichester: John Wiley \& Sons.

Croal, L. R., Jiao, Y. Q., and Newman, D. K. (2007). The fox operon from Rhodobacter strain SW2 promotes phototrophic Fe(II) oxidation in Rhodobacter capsulatus SB1003. J. Bacteriol. 189, 1774-1782.

Dutton, A. S., Fukuto, J. M., and Houk, K. N. (2005). Theoretical reduction potentials for nitrogen oxides from CBS-QB3 energetics and (C)PCM solvation calculations. Inorg. Chem. 44, 4024-4028.

Emerson, D., Fleming, E. J., and McBeth, J. M. (2010). Iron-oxidizing bacteria: an environmental and genomic perspective. Annu. Rev. Microbiol. 64, 561-583.

Feelisch, M. (1991). The biochemical pathways of nitric-oxide formation from nitrovasodilators - appropriate choice of exogenous NO donors and aspects of preparation and handling of aqueous NO solutions. J. Cardiovasc. Pharmacol. 17, S25-S33.

Ferguson, S. J., and Ingledew, W. J. (2008). Energetic problems faced by micro-organisms growing or surviving on parsimonious energy sources and at acidic pH: I. Acidithiobacillus ferrooxidans as a paradigm. Biochim. Biophys. Acta 1777, 1471-1479.

Finneran, K. T., Housewright, M. E., and Lovley, D. R. (2002). Multiple influences of nitrate on uranium solubility during bioremediation of uranium-contaminated subsurface sediments. Environ. Microbiol. 4, 510-516. 
Flores-Santana, W., Salmon, D. J., Donzelli, S., Switzer, C. H., Basudhar, D., Ridnour, L., Cheng, R., Glynn, S. A., Paolocci, N., Fukuto, J. M., Miranda, K. M., and Wink, D. A. (2011). The specificity of nitroxyl chemistry is unique among nitrogen oxides in biological systems. Antioxid. Redox Signal. 14, 1659-1674.

Gardner, A. M., Helmick, R. A., and Gardner, P. R. (2002). Flavorubredoxin, an inducible catalyst for nitric oxide reduction and detoxification in Escherichia coli. J. Biol. Chem. 277, 8172-8177.

Gomes, C. M., Giuffre, A., Forte, E., Vicente, J. B., Saraiva, L. M., Brunori, M., and Teixeira, M. (2002). A novel type of nitric-oxide reductase. Escherichia coli flavorubredoxin. J. Biol. Chem. 277, 25273-25276.

Hafenbradl, D., Keller, M., Dirmeier, R., Rachel, R., Robnagel, P., Burggraf, S., Huber, H., and Stetter, K. O. (1996). Ferroglobus placidus gen. nov., sp. nov. a novel hyperthermophilic archaeum that oxidizes $\mathrm{Fe}^{2+}$ at neutral $\mathrm{pH}$ under anoxic conditions. Arch. Microbiol. 166, 308-314.

Hansen, H. C. B., Borggaard, O. K., and Sorensen, J. (1994). Evaluation of the free-energy of formation of $\mathrm{Fe}(\mathrm{II})-\mathrm{Fe}(\mathrm{III})$ hydroxide-sulfate (green rust) and its reduction of nitrite. Geochim. Cosmochim. Acta 58, 2599-2608.

Hansen, H. C. B., Guldberg, S., Erbs, M., and Koch, C. B. (2001). Kinetics of nitrate reduction by green rusts - effects of interlayer anion and $\mathrm{Fe}(\mathrm{II}): \mathrm{Fe}(\mathrm{III})$ ratio. Appl. Clay Sci. 18, 81-91.

Hansen, H. C. B., Koch, C. B., Nanckekrogh, H., Borggaard, O. K., and Sorensen, J. (1996). Abiotic nitrate reduction to ammonium: key role of green rust. Environ. Sci. Technol. 30, 2053-2056.

Jiao, Y., and Newman, D. K. (2007). The pio operon is essential for phototrophic $\mathrm{Fe}(\mathrm{II})$ oxidation in Rhodopseudomonas palustris TIE-1. J. Bacteriol. 189, 1765-1773.

Kappler, A., Johnson, C. M., Crosby, H. A., Beard, B. L., and Newman, D. K. (2010). Evidence for equilibrium iron isotope fractionation by nitratereducing iron(II)-oxidizing bacteria. Geochim. Cosmochim. Acta 74, 2826-2842.

Kappler, A., and Newman, D. K. (2004). Formation of $\mathrm{Fe}(\mathrm{III})$-minerals by $\mathrm{Fe}(\mathrm{II})$-oxidizing photoautotrophic bacteria. Geochim. Cosmochim. Acta 68, 1217-1226.

Kappler, A., Schink, B., and Newman, D. K. (2005). Fe(III)-mineral formation and cell encrustation by the nitrate-dependent $\mathrm{Fe}$ (II)oxidizer strain BoFeN1. Geobiology 3, 235-245.

Koppenol, W. H. (1996). Thermodynamics of reactions involving nitrogen-oxygen compounds. Meth. Enzymol. 268, 7-12.

Kraft, B., Strous, M., and Tegetmeyer, H. E. (2011). Microbial nitrate respiration - genes, enzymes and environmental distribution. J. Biotechnol. $155,104-117$.

Lack, J. G., Chaudhuri, S. K., Chakraborty, R., Achenbach, L. A., and Coates, J. D. (2002). Anaerobic biooxidation of $\mathrm{Fe}(\mathrm{II})$ by Dechlorosoma suillum. Microbiol. Ecol. 43, 424-431.

Machulla, G., Thieme, J., and Niemeyer, J. (1998). "Interaction of microorganisms with soil colloids observed by X-ray microscopy," in X-Ray Microscopy and Spectroscopy, eds J. Thieme, G. Schmahl, D. Rudolph, and E. Umbach (Heidelberg: Springer-Verlag), II-21-II-28.

Mills, P. C., Rowley, G., Spiro, S., Hinton, J. C., and Richardson, D. J. (2008). A combination of cytochrome $\mathrm{c}$ nitrite reductase (NrfA) and flavorubredoxin (NorV) protects Salmonella enterica serovar Typhimurium against killing by NO in anoxic environments. Microbiology 154, 1218-1228.

Miot, J., Benzerara, K., Morin, G., Bernard, S., Beyssac, O., Larquet, E., Kappler, A., and Guyot, F. (2009a). Transformation of vivianite by anaerobic nitrate-reducing iron-oxidizing bacteria. Geobiology 7, 373-384.

Miot, J., Benzerara, K., Morin, G., Kappler, A., Obst, M., Brown, G. E., and Guyot, F. (2009b). Iron biomineralization by neutrophilic nitrate-reducing iron-oxidizing bacteria. Geochim. Cosmochim. Acta 73, A884-A884.

Miot, J., MacLellan, K., Benzerara, K., and Boisset, N. (2011). Preservation of protein globules and peptidoglycan in the mineralized cell wall of nitrate-reducing, iron(II)oxidizing bacteria: a cryo-electron microscopy study. Geobiology 9, 459-470.

Moraghan, J. T., and Buresh, R. J. (1977). Chemical reduction of nitrite and nitrous-oxide by ferrous iron. Soil Sci. Soc. Am. J. 41, 47-50.

Muehe, E. M., Gerhardt, S., Schink, B., and Kappler, A. (2009). Ecophysiology and the energetic benefit of mixotrophic $\mathrm{Fe}(\mathrm{II})$ oxidation by various strains of nitrate-reducing bacteria. FEMS Microbiol. Ecol. 70, 335-343.
Nies, D. H. (2003). Efflux-mediated heavy metal resistance in prokaryotes. FEMS Microbiol. Rev. 27, 313-339.

Ottley, C. J., Davison, W., and Edmunds, W. M. (1997). Chemical catalysis of nitrate reduction by iron(II). Geochim. Cosmochim. Acta 61 1819-1828.

Poulain, A. J., and Newman, D. K. (2009). Rhodobacter capsulatus catalyzes light-dependent $\mathrm{Fe}$ (II) oxidation under anaerobic conditions as a potential detoxification mechanism. Appl. Environ. Microbiol. 75 6639-6646.

Rodionov, D. A., Dubchak, I. L., Arkin, A. P., Alm, E. J., and Gelfand, M. S. (2005). Dissimilatory metabolism of nitrogen oxides in bacteria: comparative reconstruction of transcriptional networks. PLoS Comput. Biol. 1, e55. doi:10.1371/journal.pcbi.0010055

Schoepp-Cothenet, B., Lieutaud, C., Baymann, F., Vermeglio, A. Friedrich, T., Kramer, D. M., and Nitschke, W. (2009). Menaquinone as pool quinone in a purple bacterium. Proc. Natl. Acad. Sci. U.S.A. 106, 8549-8554.

Shafirovich, V., and Lymar, S. V. (2002). Nitroxyl and its anion in aqueous solutions: spin states, protic equilibria, and reactivities toward oxygen and nitric oxide. Proc. Natl. Acad. Sci. U.S.A. 99, 7340-7345.

Straub, K. L., Benz, M., Schink, B. and Widdel, F. (1996). Anaerobic, nitrate-dependent microbial oxidation of ferrous iron. Appl. Environ. Microbiol. 62, 1458-1460.

Straub, K. L., and Buchholz-Cleven, B. E. E. (1998). Enumeration and detection of anaerobic ferrous ironoxidizing, nitrate-reducing bacteria from diverse European sediments. Appl. Environ. Microbiol. 64, 4846-4856.

Summers, D. P., and Chang, S. (1993). Prebiotic ammonia from reduction of nitrite by iron (II) on the early Earth. Nature 365, 630-633.

Turk, T., and Hollocher, T. C. (1992). Oxidation of dithiothreitol during turnover of nitric oxide reductase: evidence for generation of nitroxyl with the enzyme from Paracoccus denitrificans. Biochem. Biophys. Res. Commun. 183, 983-988.

Wagner, G. C., Kassner, R. J., and Kamen, M. D. (1974). Redox potentials of certain vitamins $\mathrm{K}$ : implications for a role in sulfite reduction by obligately anaerobic bacteria. Proc. Natl. Acad. Sci. U.S.A. 71 , 253-256.
Weber, K. A., Achenbach, L. A., and Coates, J. D. (2006a). Microorganisms pumping iron: anaerobic microbial iron oxidation and reduction. Nat. Rev. Microbiol. 4, 752-764. Weber, K. A., Pollock, J., Cole, K. A., O'Connor, S. M., Achenbach, L. A., and Coates, J. D. (2006b). Anaerobic nitrate-dependent iron(II) bio-oxidation by a nove lithoautotrophic betaproteobacterium, strain 2002. Appl. Environ. Microbiol. 72, 686-694.

Weber, K. A., Urrutia, M. M., Churchill, P. F., Kukkadapu, R. K., and Roden, E. E. (2006c). Anaerobic redox cycling of iron by freshwater sediment microorganisms. Environ. Microbiol. 8, 100-113.

Weber, K. A., Hedrick, D. B., Peacock, A. D., Thrash, J. C., White, D. C., Achenbach, L. A., and Coates, J. D. (2009). Physiological and taxonomic description of the novel autotrophic, metal oxidizing bacterium, Pseudogulbenkiania sp. strain 2002. Appl. Microbiol. Biotechnol. 83, 555-565.

Weber, K. A., Picardal, F. W., and Roden, E. E. (2001). Microbially catalyzed nitrate-dependent oxidation of biogenic solid-phase Fe(II) compounds. Environ. Sci. Technol. 35, 1644-1650.

Widdel, F., Schnell, S., Heising, S., Ehrenreich, A., Assmus, B., and Schink, B. (1993). Ferrous iron oxidation by anoxygenic phototrophic bacteria. Nature 362, 834-836.

Conflict of Interest Statement: The authors declare that the research was conducted in the absence of any commercial or financial relationships that could be construed as a potential conflict of interest.

Received: 03 November 2011; paper pending published: 07 December 2011; accepted: 02 February 2012; published online: 20 February 2012.

Citation: Carlson HK, Clark IC, Melnyk RA and Coates JD (2012) Toward a mechanistic understanding of anaerobic nitrate-dependent iron oxidation: balancing electron uptake and detoxification. Front. Microbio. 3:57. doi: 10.3389/fmicb.2012.00057

This article was submitted to Frontiers in Microbiological Chemistry, a specialty of Frontiers in Microbiology.

Copyright (c) 2012 Carlson, Clark, Melnyk and Coates. This is an open-access article distributed under the terms of the Creative Commons Attribution Non Commercial License, which permits noncommercial use, distribution, and reproduction in other forums, provided the original authors and source are credited. 